\title{
New thermoplastic poly(carbonate-urethane) elastomers
}

\author{
Anna Kultys*, Magdalena Rogulska \\ Maria Curie-Skłodowska University, Department of Polymer Chemistry, Faculty of Chemistry, ul. Gliniana 33, \\ 20-614 Lublin, Poland \\ * Corresponding author: e-mail address: akultys@umcs.pl
}

\begin{abstract}
Two series of novel thermoplastic poly(carbonate-urethane) elastomers, with different hard-segment content (30-60 wt \%), were synthesized by melt polymerization from poly(hexane-1,6-diyl carbonate) diol of $\bar{M}_{n}$ $=2000$ as a soft segment, 4,4'-diphenylmethane diisocyanate (MDI) or hexane-1,6-diyl diisocyanate (HDI) and 6,6'-[methylenebis(1,4-phenylenemethylenethio)]dihexan-1-ol as a chain extender. The structure and basic properties of the polymers were examined by Fourier transform infrared spectroscopy, X-ray diffraction analysis, atomic force microscopy, differential scanning calorimetry, thermogravimetric analysis, Shore hardness and tensile tests. The resulting TPUs were colorless polymers, showing almost amorphous structures. The MDI-based TPUs showed higher tensile strengths (up to 21.3 MPa vs. 15.8 MPa) and elongations at break (up to $550 \%$ vs. $425 \%$ ), but poorer low-temperature properties than the HDI-based analogs.
\end{abstract}

Keywords: thermoplastic polyurethane elastomers; poly(hexane-1,6-diyl carbonate) diol; 4,4'-diphenylmethane diisocyanate; hexane-1,6-diyl diisocyanate; thermal and mechanical properties; atomic force microscopy.

\section{INTRODUCTION}

Thermoplastic polyurethane elastomers (TPUs) are commonly used nowadays due to their unique set of properties, such as excellent elasticity, tensile and breaking strength, very good abrasion and tear properties, as well as good chemical resistance. They are mainly employed in medicine, car industry, shoe manufacturing, building and construction market. TPUs are block copolymers, often called segmented, whose macromolecules consist of alternating hard blocks (segments), built from diisocyanate and short-chain diol (chain extender), and soft segments formed by polymer diol. Conventional TPUs are synthesized by using both aromatic and aliphatic diisocyanates (mainly 4,4'-diphenylmethane diisocyanate (MDI), 4,4'dicyclohexylmethane diisocyanate and hexane-1,6-diyl diisocyanate (HDI)), aliphatic diols as chain extenders (mostly butane-1,4-diol), and polyester, polyether or polycarbonate diols. Polyester diols produce TPUs with higher mechanical strength, harder and less extensible than polyether diols. Polyether TPUs show better hydrolytic resistance in comparison with polyester TPUs, which in turn are more resistant to UV radiation ${ }^{1}$. Both drawbacks can be eliminated when replacing polyester or polyether segments by hydrolytically and oxidativelly stable polycarbonate segments, most often by using poly(hexane1,6-diyl-ethylene carbonate) diol and poly(hexane-1,6-diyl carbonate) diol (PHC $)^{2-5}$. This allowed to obtain a new generation of biomedical polymers ${ }^{5-7}$.

The purpose of this work was to synthesize and characterize new TPUs with polycarbonate soft segment by using PHC of $\bar{M}_{n}=2000$, HDI or MDI and unconventional chain extender containing sulfide linkages in its structure, i.e. 6,6'-[methylenebis(1,4-phenylenemethylenethio)] dihexan-1-ol (diol H). In this study we discuss the influence of the kind of diisocyanate used as well as the content of the hard segments $(30-60$ wt. \%) on morphology, crystallinity and some physicochemical, thermal and mechanical properties of new TPUs. Because the structure of the newly obtained TPUs incorporates sulfur atoms, they can exhibit an improved antimicrobial activity and adhe- sive properties as compared to the conventional TPUs ${ }^{8-10}$. The antimicrobial activity and adhesive properties of the TPUs are still under investigation and will be described and discussed in the next publication.

\section{EXPERIMENTAL}

\section{Materials}

6,6'-[Methylenebis(1,4-phenylenemethylenethio)] dihexan-1-ol (diol H), m.p. $=67-68^{\circ} \mathrm{C}$, was obtained by the condensation reaction of (methylenedi-1,4phenylene)dimethanethiol with 6-chlorohexan-1-ol in 10\% aqueous solution of sodium hydroxide ${ }^{11}$. Before being used, PHC from Aldrich Chemical Company (Milwaukee, USA) were heated at $90^{\circ} \mathrm{C}$ in vacuo for $10 \mathrm{~h}$. MDI (98\%) and HDI (>99\%) from Sigma-Aldrich (Steinheim, Germany) and dibutyltin dilaurate (DBTDL) from MerckSchuchardt (Hohenbrunn, Germany) were used as received.

\section{Measurements}

Reduced viscosities $\left(\eta_{\text {red }} \mathrm{s}, \mathrm{dL} / \mathrm{g}\right)$ of $0.5 \%$ polymer solution in 1,1,2,2-tetrachloroethane (TChE) were measured in an Ubbelohde viscometer (Gliwice, Poland) at $25^{\circ} \mathrm{C}$. Fourier transform infrared (FT-IR) spectra were obtained in the transmission mode with a Perkin-Elmer $1725 \mathrm{X}$ FT-IR spectrophotometer using thin films. The thermogravimetric analysis (TGA) was performed on a MOM 3427 derivatograph (Paulik, Paulik and Erdey, Budapest, Hungary) at the heating rate of $10{ }^{\circ} \mathrm{C} / \mathrm{min}$ in air; $\mathrm{Al}_{2} \mathrm{O}_{3}$ was used as a standard substance. Differential scanning calorimetry (DSC) thermograms were obtained with a Netzsch 204 calorimeter (Günzbung, Germany) in the range of $-100^{\circ} \mathrm{C}$ to $200^{\circ} \mathrm{C}$. The reported transitions were taken from the first and second heating scans. The scans were performed at the heating/cooling rate of $10^{\circ} \mathrm{C} /$ min under nitrogen atmosphere (flow $=30 \mathrm{~cm}^{3} / \mathrm{min}$ ). The sample weights about $10 \mathrm{mg}$ were used. Glass-transition temperatures $\left(T_{\mathrm{g}} \mathrm{s}\right)$ for the polymer samples were taken as the inflection point on the curves of the heat- 
capacity changes. The melting temperatures $\left(T_{\mathrm{m}} \mathrm{s}\right)$ were read at the endothermic-peak maxima. The X-ray diffraction (XRD) measurements were performed using a DRON3 X-ray apparatus (St. Petersburg, Russia) with a copper tube and nickel filter. The XRD patterns of the investigated samples were obtained by measuring the number of impulses within a given angle over $10 \mathrm{~s}$. The measurements were taken every $0.04^{\circ}$. The XRD patterns were analyzed by WAXSFIT computer program ${ }^{\mathbf{1 2}}$. The program resolves a diffraction curve on diffraction peaks and amorphous halo which allows estimating the crystallinity degree. Atomic force microscopy (AFM) was carried out on a Multimode (Digital Instruments, CA) microscope in tapping mode in air. The phase data were recorded simultaneously. Silicon probes were used (TESP, Digital Instruments, CA) with a nominal spring constant of $20-100$ $\mathrm{N} / \mathrm{m}$. In order to compare the structure of all the investigated samples, the imaging parameters were kept constant. Phase images at 5 and $1 \mu \mathrm{m}$ scan sizes were obtained by using a hard tapping technique. The specimens used were the cuttings from crude polymers after their one-month conditioning at room temperature. The hardness of the polymers was measured by the Shore A/D method on a Zwick 7206/H04 hardness tester (Germany) at $23^{\circ} \mathrm{C}$. The values were taken after $15 \mathrm{~s}$. Tensile testing was performed on a TIRA Test 2200 tensile-testing machine according to Polish Standard PN-81/C-89034 (EN ISO Standard 527-1:1996 and 527-2:1996) at the speed of $100 \mathrm{~mm} / \mathrm{min}$ at $23^{\circ} \mathrm{C}$; the tensile test pieces $1 \mathrm{~mm}$ thick and $6 \mathrm{~mm}$ wide (for the section measured) were cut from the pressed sheet.

\section{TPU synthesis}

TPUs with hard-segment content of 30, 40, 50 and 60 wt $\%$ were prepared, according to Scheme 1, by a one-step melt polymerization process from HDI or MDI, diol $\mathrm{H}$ and $\mathrm{PHC}$. The polymerization reaction was conducted at the $\mathrm{NCO} / \mathrm{OH}$ molar ratio of 1 and in the presence of DBTDL as a catalyst in the case of using the less reactive aliphatic diisocyanate.

The general procedure for the synthesis of the MDIbased TPUs by this method was as follows. The diol $\mathrm{H}$ and PHC (0.01 mol together) were heated under dry nitrogen to $110^{\circ} \mathrm{C}$ in an oil bath. MDI $(0.01 \mathrm{~mol})$ was added to the melted and mixed dihydroxy compounds and the reaction was continued until the increase in viscosity made stirring impossible. Then the reaction temperature was gradually raised to $130^{\circ} \mathrm{C}$ and the formed colorless, rub- ber-like product was conditioned at this temperature for $2 \mathrm{~h}$.

The general procedure for the synthesis of the HDIbased TPUs by this method was as follows. The diol $\mathrm{H}$ and PHC (0.01 mol together) and HDI (0.01 mol) were heated with stirring under dry nitrogen to $110^{\circ} \mathrm{C}$ in an oil bath. A catalytic amount of DBTDL (about $0.03 \mathrm{~g}$ ) was added to the formed clear melt and polymerization rapidly began at vigorous stirring. The reaction temperature was gradually raised to $130^{\circ} \mathrm{C}$ and the formed colorless rubber-like product was additionally heated at this temperature for $2 \mathrm{~h}$.

\section{RESULTS AND DISCUSSION}

\section{TPU characterization}

The resulting TPUs were colorless materials. Their designations and $\eta_{\text {red }}$ values are listed in Table 1 . The $\eta_{\text {red }}$ values determined for all polymers, ranging from 0.69 to $0.86 \mathrm{dL} / \mathrm{g}$, point to their relatively high molecular weights. The MDI-based TPUs showed lower resistance to organic solvents at room temperature than the HDI-based TPUs. They were soluble in TChE, $N$-methyl-2-pyrrolidone (NMP), $N, N$-dimethylformamide, $N, N$-dimethylacetamide and tetrahydrofuran, whereas all the TPUs based on HDI were soluble only in TChE and polymers H30 and H40 also in NMP.

The chemical structures of the TPUs were examined by FT-IR spectroscopy.

FT-IR $\left(\mathrm{cm}^{-1}\right)$ of the HDI-based TPUs: $3320-3319$ (N$\mathrm{H}$ stretching) and $1537-1535$ (N-H bending) of the urethane group; 1745-1744 $(\mathrm{C}=\mathrm{O}$ stretching of the carbonate group and nonbonded $\mathrm{C}=\mathrm{O}$ stretching of the urethane group); 1686-1685 (bonded $\mathrm{C}=\mathrm{O}$ stretching of the urethane group); 2939-2937 and 2862-2859 (asymmetric and symmetric C-H stretching of $\mathrm{CH}_{2}$, respectively); 1466-1465 (benzene ring); 1262-1259 (C-O stretching of the carbonate group).

FT-IR $\left(\mathrm{cm}^{-1}\right)$ of the MDI-based TPUs: $3352-3339(\mathrm{~N}-$ $\mathrm{H}$ stretching) and 1531-1530 (N-H bending) of the urethane group; 1743-1741 $(\mathrm{C}=\mathrm{O}$ stretching of the urethane and carbonate groups); 2938-2936 and 28612859 (asymmetric and symmetric C-H stretching of $\mathrm{CH}_{2}$, respectively); 1598-1597 and 1464-1462 (benzene ring); 1260-1259 (C-O stretching of the carbonate group).

All the spectra exhibited significant absorptions of the urethane and carbonate groups, benzene ring and methylene group. The absorption characteristic of $\mathrm{H}$-bonded $\mathrm{C}=\mathrm{O}$ stretching of the urethane group was shown only in

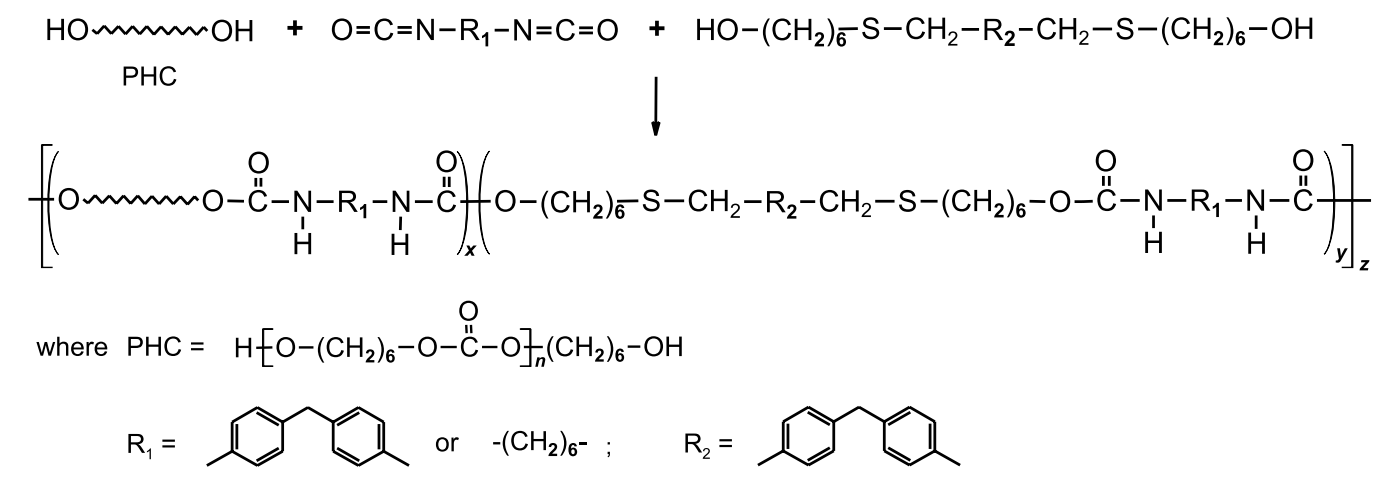

Scheme 1. 
Table 1. Designations, $\eta_{\text {red }}$ values and TGA data of the TPUs

\begin{tabular}{|c|c|c|c|c|c|c|c|}
\hline \multirow{2}{*}{ TPU } & \multirow{2}{*}{ Diisocyanate } & \multirow{2}{*}{$\begin{array}{l}\text { Hard-segment content } \\
\text { (wt. \%) }\end{array}$} & \multirow{2}{*}{$\begin{array}{c}\eta_{\mathrm{red}} \\
(\mathrm{dl} / \mathrm{g})\end{array}$} & \multicolumn{4}{|c|}{$\left({ }^{\circ} \mathrm{C}\right)$} \\
\hline & & & & $T_{5}^{\mathrm{a}}$ & $T_{10}^{a}$ & $T_{50}{ }^{a}$ & $T_{\max }^{\mathrm{b}}$ \\
\hline $\mathrm{H} 30$ & \multirow{4}{*}{ HDI } & 30 & 0.74 & 320 & 340 & 375 & $380,465,580$ \\
\hline $\mathrm{H} 40$ & & 40 & 0.74 & 325 & 340 & 380 & $380,465,580$ \\
\hline $\mathrm{H} 50$ & & 50 & 0.83 & 320 & 335 & 370 & $370,460,575$ \\
\hline $\mathrm{H} 60$ & & 60 & 0.75 & 320 & 330 & 380 & $370,460,570$ \\
\hline M30 & \multirow{4}{*}{ MDI } & 30 & 0.86 & 330 & 340 & 375 & $375,480,650$ \\
\hline M40 & & 40 & 0.71 & 320 & 335 & 370 & $370,480,650$ \\
\hline M50 & & 50 & 0.69 & 320 & 330 & 370 & $360,480,650$ \\
\hline M60 & & 60 & 0.83 & 320 & 335 & 375 & $360,500,640$ \\
\hline
\end{tabular}

${ }^{a}$ The temperature of 5,10 and $50 \%$ mass loss from the thermogravimetric (TG) curve, respectively.

${ }^{\mathrm{b}}$ The temperature of the maximum rate of mass loss from the differential TG curve.

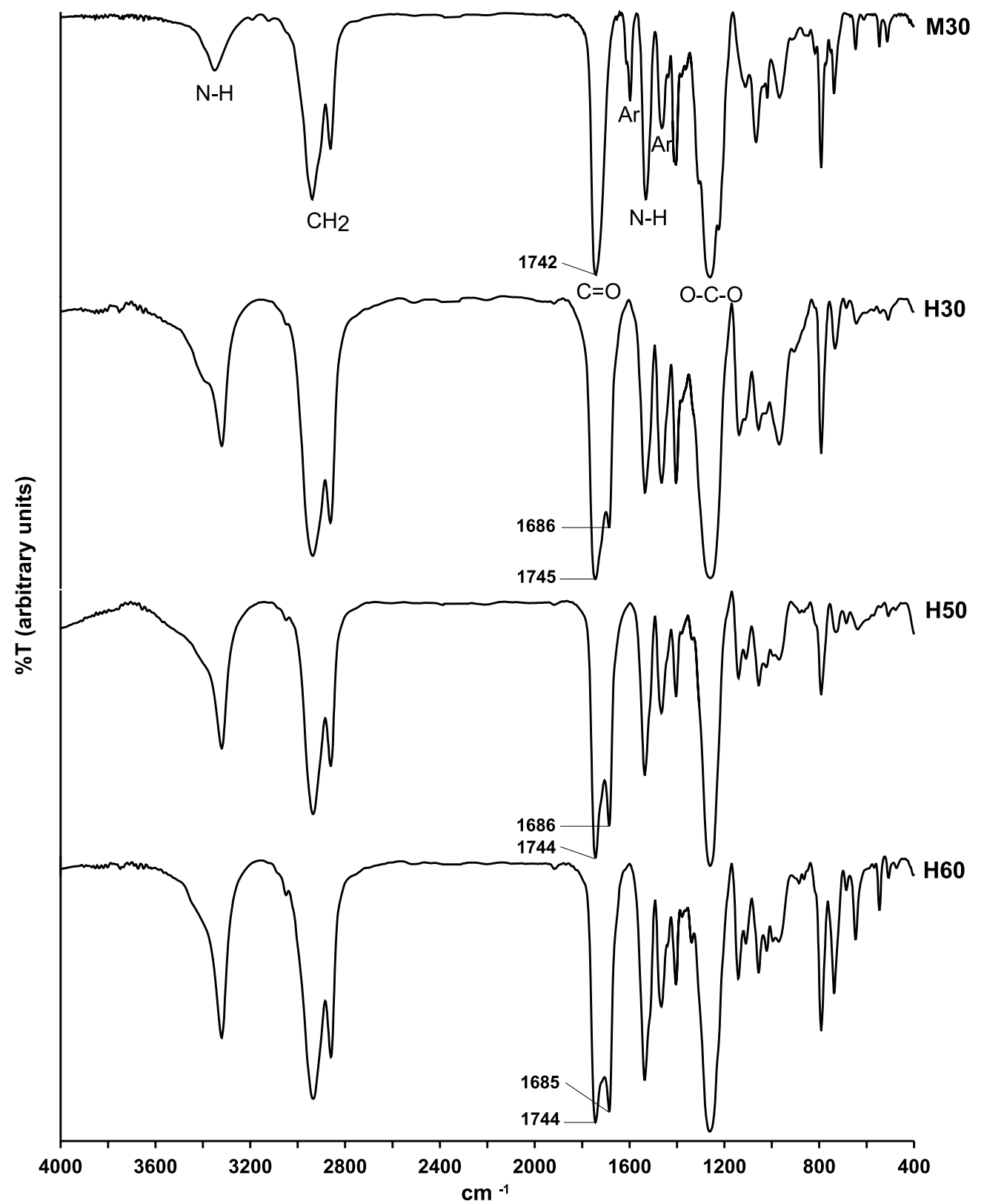

Figure 1. FT-IR spectra of TPUs M30, H30, H50 and H60

the spectra of the HDI-based TPUs. Figure 1 presents the typical FT-IR spectra of TPUs M30, H30, H50 and H60.

\section{Thermal properties}

Thermogravimetric analysis (TGA)

The data received, as given in Table 1, point to only slight influence of the kind of diisocyanate used on the decomposition process of the TPUs. The decomposition, both of the polymers based on HDI and MDI, occurred in three stages. The first stage can be ascribed to simultaneous decomposition of carbonate, urethane and sulfide linkages; the second was associated with the aromatic content in the polymer, whereas the last stage was connected with the oxidation of the char formed in the previous stages ${ }^{13}$. All the synthesized TPUs exhibited a relatively good thermal stability. Their $5 \%$ and $10 \%$ mass 
Table 2. DSC data of the TPUs, PHC, H100 and M100

\begin{tabular}{|c|c|c|c|c|c|c|}
\hline \multirow{2}{*}{ Polymer } & $T_{\mathrm{g}}\left({ }^{\circ} \mathrm{C}\right)$ & $T_{\mathrm{g}}\left({ }^{\circ} \mathrm{C}\right)$ & $T_{\mathrm{m}}\left({ }^{\circ} \mathrm{C}\right)$ & $T_{\mathrm{m}}\left({ }^{\circ} \mathrm{C}\right)$ & $\Delta H_{\mathrm{m}}(\mathrm{J} / \mathrm{g})$ & $\Delta H_{\mathrm{m}}(\mathrm{J} / \mathrm{g})$ \\
\hline & $1^{\mathrm{a}}$ & $\mathrm{II}^{\mathrm{a}}$ & $\mathrm{I}^{\mathrm{a}}$ & $\mathrm{II}^{\mathrm{a}}$ & $I^{a}$ & $I^{\mathrm{a}}$ \\
\hline $\mathrm{PHC}$ & -58.5 & -56.0 & $11.5,36.8$ & 36.7 & 56.1 & 32.5 \\
\hline $\mathrm{H} 30$ & -43.8 & -37.0 & $62.6,105.3$ & 102.8 & 27.6 & 19.3 \\
\hline $\mathrm{H} 40$ & -42.2 & -39.1 & $58.6,112.8$ & 109.3 & 33.4 & 23.0 \\
\hline $\mathrm{H} 50$ & -42.1 & -38.4 & $57.3,115.2$ & 112.3 & 42.4 & 27.9 \\
\hline $\mathrm{H} 60$ & -36.5 & -33.8 & $54.9,116.7$ & 114.3 & 50.7 & 44.6 \\
\hline $\mathrm{H} 100$ & & 7.1 & 120.4 & 120.0 & 61.0 & 41.8 \\
\hline M30 & -30.0 & -14.3 & $71.3,101.7$ & & 14.2 & \\
\hline M40 & -27.9 & -9.6 & $62.7,106.7$ & & 20.2 & \\
\hline M50 & -25.8 & -3.6 & $59.9,112.1$ & & 24.3 & \\
\hline M60 & -0.5 & 7.2 & $58.4,116.3$ & & 26.4 & \\
\hline M100 & 19.3 & 44.8 & 123.9 & & 49.5 & \\
\hline
\end{tabular}

${ }^{\mathrm{a}} \mathrm{I}$ and II: first and second heating scans, respectively.

Table 3. XRD data of the TPUs

\begin{tabular}{|c|c|c|c|c|c|c|c|c|c|c|}
\hline \multirow[t]{2}{*}{ TPU } & \multicolumn{2}{|c|}{$\begin{array}{c}\text { Crystallinity degree } \\
(\%)\end{array}$} & \multicolumn{2}{|c|}{$\begin{array}{l}2 \theta \\
\left({ }^{\circ}\right)\end{array}$} & \multicolumn{2}{|c|}{$\begin{array}{c}\text { FWHM } \\
\left({ }^{\circ}\right)\end{array}$} & \multicolumn{2}{|c|}{$\begin{array}{l}\text { Height of diffraction peak } \\
\text { (arbitrary units) }\end{array}$} & \multicolumn{2}{|c|}{$\begin{array}{c}\text { Area of } \\
\text { diffraction peak } \\
\text { (arbitrary units) }\end{array}$} \\
\hline & $\mathrm{H}$ & $M$ & $\mathrm{H}$ & $M$ & $\mathrm{H}$ & $\mathrm{M}$ & $\mathrm{H}$ & $M$ & $\mathrm{H}$ & $\mathrm{M}$ \\
\hline \multirow{7}{*}{30} & \multirow{7}{*}{1.9} & \multirow{7}{*}{1.3} & 11.8 & 11.3 & 4.4 & 4.5 & 11 & 8 & 5.4 & 3.7 \\
\hline & & & 16.2 & 16.7 & $0.5^{\mathrm{a}}$ & $1.0^{\mathrm{a}}$ & 3 & 4 & 0.2 & 0.6 \\
\hline & & & 20.1 & 19.8 & 3.2 & 2.0 & 8 & 15 & 3.1 & 3.2 \\
\hline & & & 20.6 & 20.5 & 6.8 & 7.2 & 100 & 100 & 100.0 & 100.0 \\
\hline & & & 23.2 & 23.0 & $1.0^{\mathrm{a}}$ & $1.1^{\mathrm{a}}$ & 19 & 9 & 2.2 & 1.0 \\
\hline & & & 25.4 & 26.3 & 2.1 & 1.7 & 7 & 8 & 2.5 & 2.2 \\
\hline & & & 42.4 & 42.6 & 19.0 & 14.2 & 7 & 7 & 15.8 & 10.5 \\
\hline \multirow{9}{*}{40} & \multirow{9}{*}{1.0} & \multirow{9}{*}{2.6} & 11.7 & 11.1 & 4.7 & 4.0 & 11 & 6 & 5.8 & 2.4 \\
\hline & & & 19.6 & 15.6 & 2.0 & $0.4^{a}$ & 18 & 3 & 4.4 & 0.2 \\
\hline & & & 20.9 & 16.8 & 7.1 & $0.9^{\mathrm{a}}$ & 100 & 7 & 100.0 & 0.7 \\
\hline & & & 23.2 & 19.7 & $1.0^{\mathrm{a}}$ & 2.1 & 7 & 18 & 1.0 & 4.1 \\
\hline & & & 32.2 & 20.4 & $1.1^{\mathrm{a}}$ & 7.1 & 1 & 100 & 0.2 & 100.0 \\
\hline & & & 42.6 & 22.9 & 14.0 & $1.2^{\mathrm{a}}$ & 7 & 16 & 11.2 & 2.0 \\
\hline & & & & 24.6 & & $0.6^{\mathrm{a}}$ & & 4 & & 0.3 \\
\hline & & & & 26.1 & & 1.9 & & 11 & & 3.3 \\
\hline & & & & 42.7 & & 14.8 & & 8 & & 11.8 \\
\hline \multirow{7}{*}{50} & \multirow{7}{*}{0.9} & \multirow{7}{*}{2.3} & 11.7 & 11.8 & 4.4 & 6.5 & 10 & 30 & 5.2 & 18.5 \\
\hline & & & 19.6 & 17.1 & 2.1 & $0.6^{\mathrm{a}}$ & 15 & 8 & 3.4 & 0.5 \\
\hline & & & 20.9 & 19.5 & 7.3 & 8.3 & 100 & 100 & 100.0 & 100.0 \\
\hline & & & 23.1 & 20.4 & $0.9^{\mathrm{a}}$ & 1.8 & 11 & 12 & 1.1 & 2.1 \\
\hline & & & 42.1 & 23.3 & 15.3 & $1.4^{\mathrm{a}}$ & 8 & 13 & 12.9 & 2.5 \\
\hline & & & & 26.5 & & 1.6 & & 8 & & 1.9 \\
\hline & & & & 39.9 & & 8.6 & & 3 & & 2.8 \\
\hline \multirow{7}{*}{60} & \multirow{7}{*}{1.6} & \multirow{7}{*}{2.2} & 11.6 & 12.3 & 4.4 & 8.6 & 11 & 13 & 5.3 & 13.0 \\
\hline & & & 19.7 & 16.7 & 2.2 & $1.4^{\mathrm{a}}$ & 18 & 6 & 5.3 & 0.9 \\
\hline & & & 20.7 & 19.6 & 7.3 & 6.9 & 17 & 100 & 100.0 & 100.0 \\
\hline & & & 23.1 & 20.5 & $1.0^{\mathrm{a}}$ & $0.8^{\mathrm{a}}$ & 5 & 16 & 2.0 & 2.0 \\
\hline & & & 25.4 & 23.1 & 1.7 & 1.7 & 100 & 23 & 1.4 & 5.3 \\
\hline & & & 41.9 & 25.9 & 15.2 & 2.9 & 8 & 12 & 13.6 & 3.9 \\
\hline & & & & 40.2 & & 11.1 & & 5 & & 6.1 \\
\hline
\end{tabular}

${ }^{a}$ Crystalline peak.

loss took place in the temperature range of $320-330^{\circ} \mathrm{C}$ and $330-340^{\circ} \mathrm{C}$, respectively.

Differential scanning calorimetry (DSC)

The obtained numerical data $\left(T_{g}, T_{m}\right.$ and heat of melting $\left(\Delta H_{\mathrm{m}}\right)$ values) for all the TPUs as well as PHC and regular polyurethanes, forming the hard segments in the TPUs, prepared from diol $\mathrm{H}$ and HDI (H100) or MDI (M100) $)^{\mathbf{1 1}, \mathbf{1 3}}$ are summarized in Table 2, while the DSC curves of all the TPUs are presented in Figures 2 and 3.
The DSC curves of all the TPUs from the first heating scans besides glass transition showed two endothermic peaks with maxima in the range of $54.9-71.3^{\circ} \mathrm{C}$ and $101.7-116.7^{\circ} \mathrm{C}$, corresponding to the melting of the less or the better ordered hard-segment domains, respectively. Both smaller $\Delta H_{\mathrm{m}}$ values and the lack of endothermic peaks in the second heating scans in the case of the TPUs from MDI indicate their lower tendency for the forming of ordered structures in comparison with the analogous polymers from HDI. The TPUs based on HDI showed 


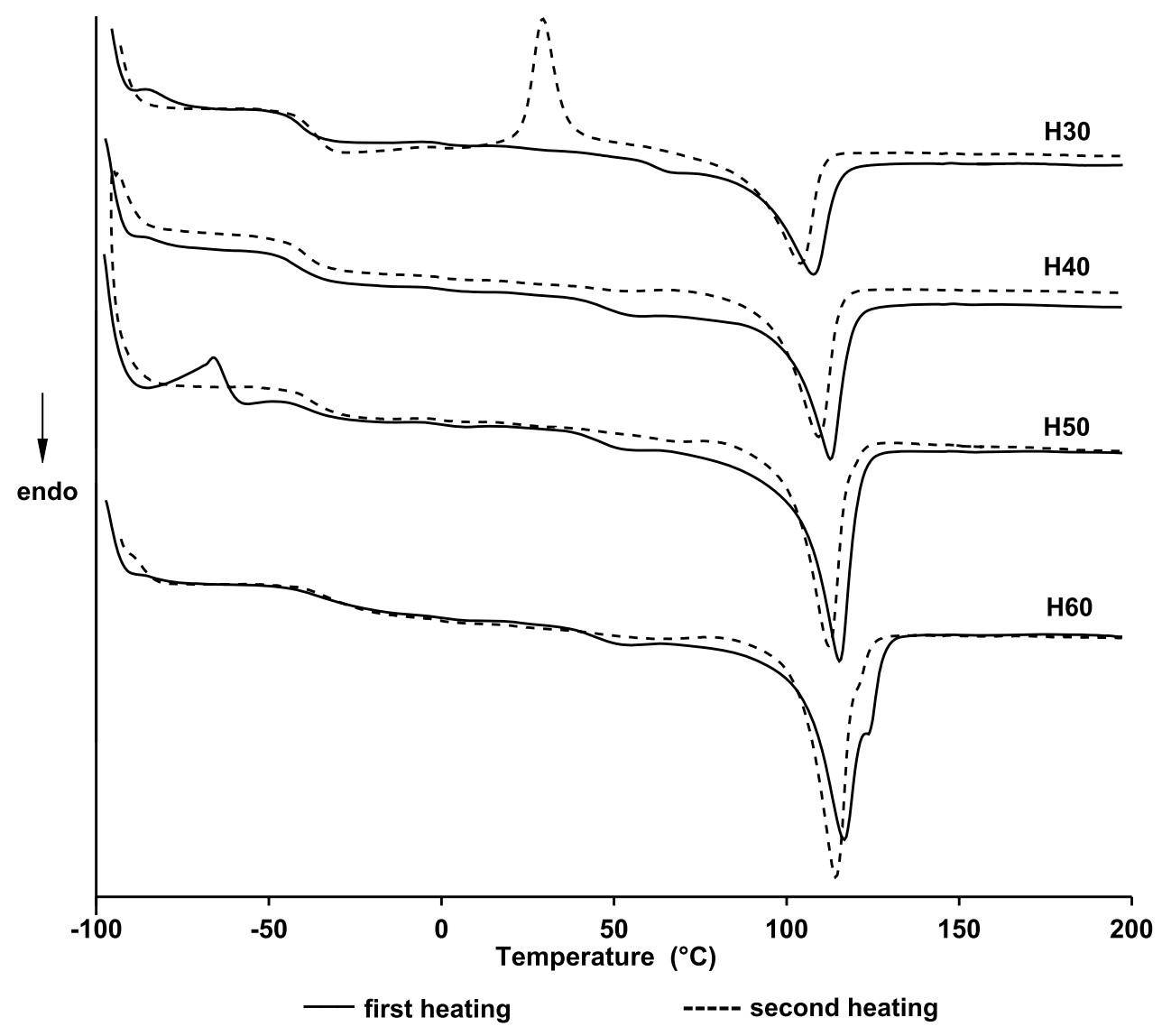

Figure 2. The DSC curves of the HDI-based TPUs

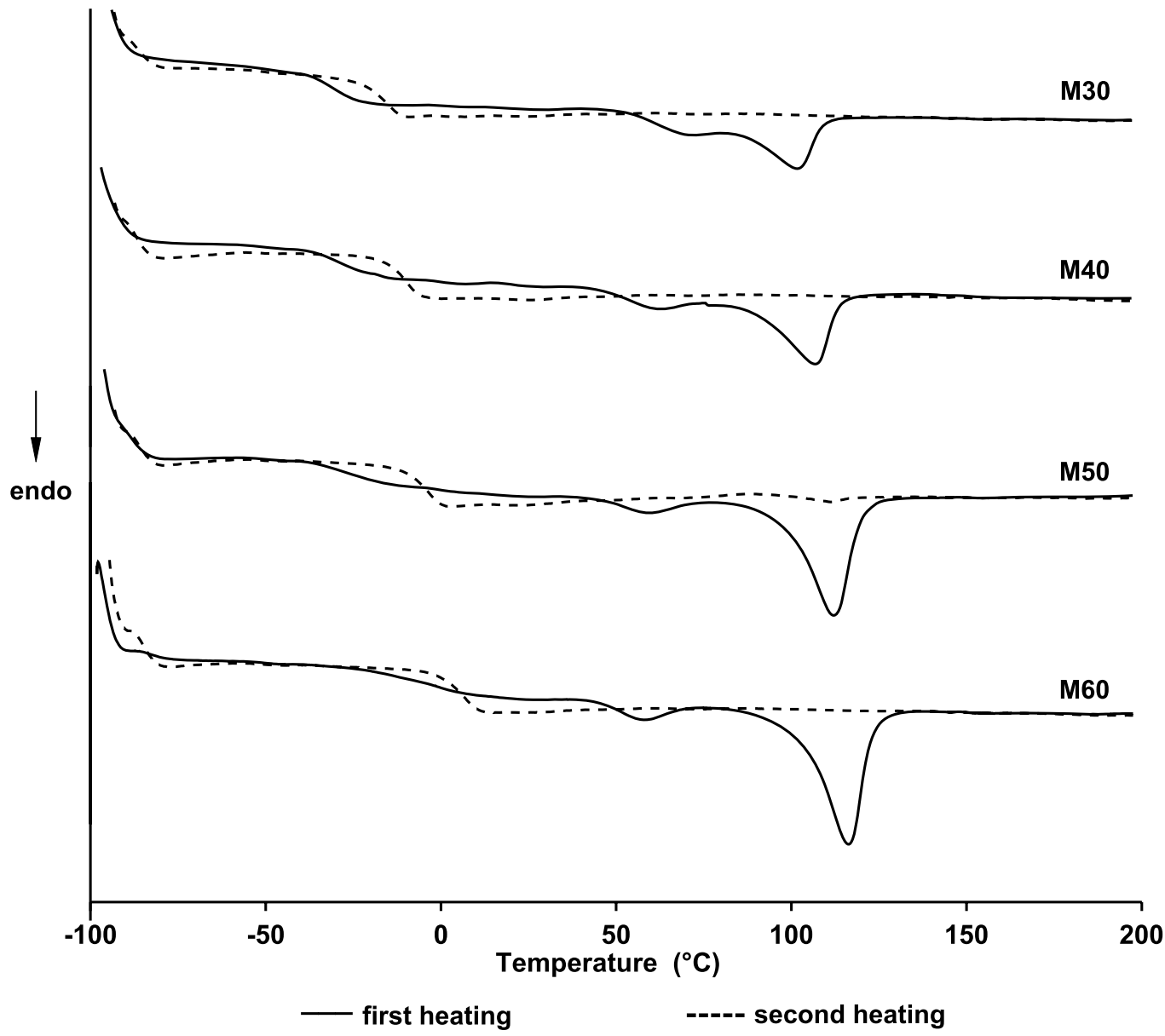

Figure 3. The DSC curves of the MDI-based TPUs 

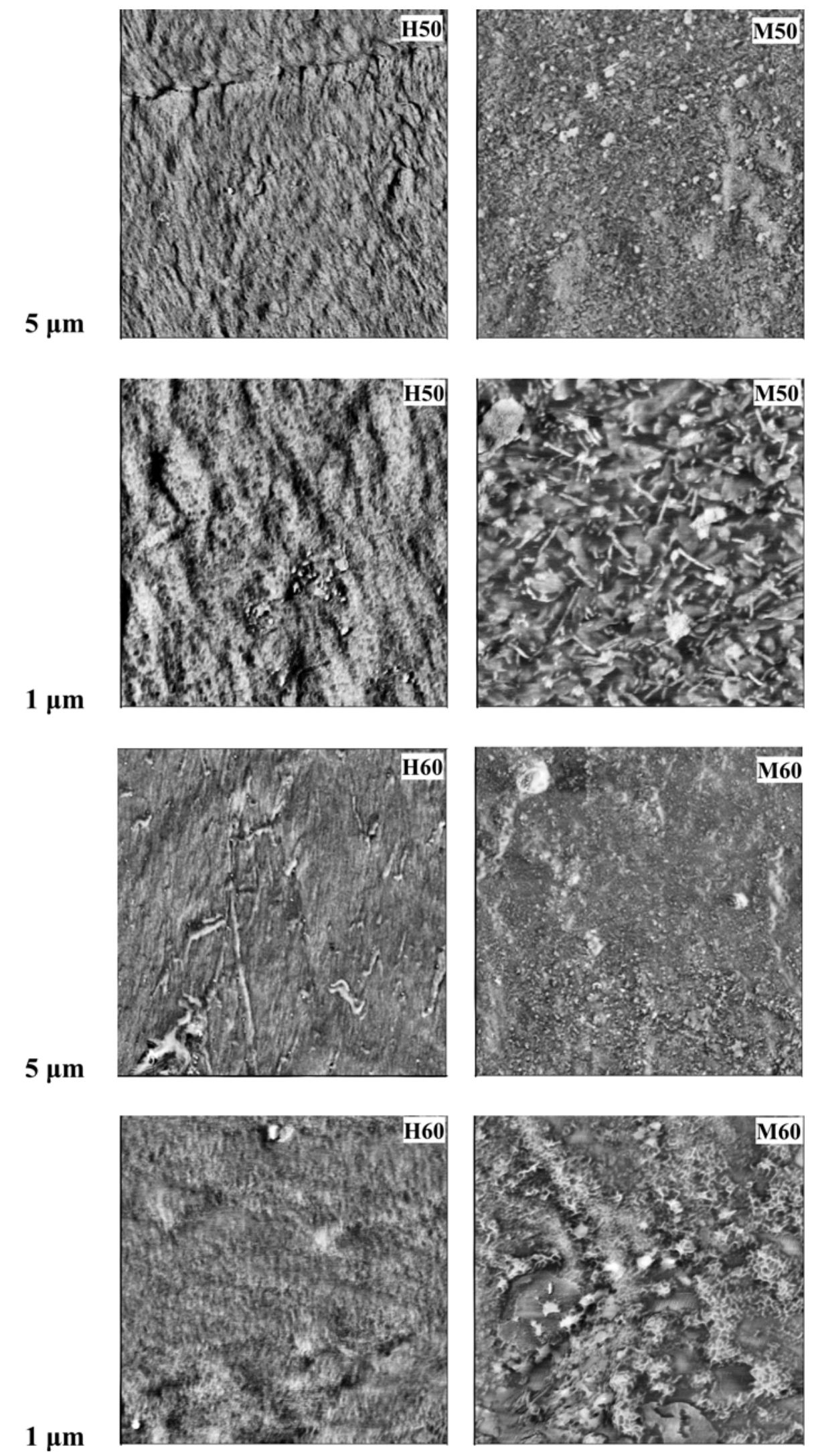

Figure 4. The AFM phase images of TPUs H50, H60, M50 and M60 at 5 and $1 \mu \mathrm{m}$ scan sizes

much lower $T_{\mathrm{g}} \mathrm{s}$ (from $-43.8^{\circ} \mathrm{C}$ to $-36.5^{\circ} \mathrm{C}$ vs. from $-30.0^{\circ} \mathrm{C}$ to $-0.5^{\circ} \mathrm{C}$ ) and higher degree of microphase separation (the $T_{\mathrm{g}}$ values more similar to the value received for PHC) than the polymers from MDI.

In both series the lowering of the degree of microphase separation, more clearly marked in MDI series, was observed for polymers with $60 \mathrm{wt}$. \% content of the hard segments.
To confirm the presence of the microphase separated morphology of the TPUs, indirectly deduced by DSC, tapping mode AFM experiments were performed. Tapping mode AFM generates phase images with dark features corresponding to regions of lower modulus (soft-segmentrich domains) and bright features corresponding to regions of higher modulus (hard-segment-rich domains). For these studies the polymers with higher contents of the 
Table 4. Mechanical properties of the TPUs

\begin{tabular}{|c|c|c|c|c|c|}
\hline TPU & $\begin{array}{c}\text { Hardness } \\
(\text { Shore A/D) }\end{array}$ & $\begin{array}{c}\text { Modulus } \\
\text { of elasticity } \\
(\mathrm{MPa})\end{array}$ & $\begin{array}{c}\text { Tensile } \\
\text { strength } \\
(\mathrm{MPa})\end{array}$ & $\begin{array}{c}\text { Elongation } \\
\text { at break } \\
(\%)\end{array}$ & $\begin{array}{c}\text { Pressing temperature } \\
\left({ }^{\circ} \mathrm{C}\right)\end{array}$ \\
\hline $\mathrm{H} 30$ & $87 / 24$ & 28.9 & 12.0 & 425 & 100 \\
\hline $\mathrm{H} 40$ & $85 / 26$ & 65.8 & 14.0 & 400 & 105 \\
\hline $\mathrm{H} 50$ & $92 / 29$ & 124.4 & 15.8 & 325 & 110 \\
\hline $\mathrm{H} 60$ & $95 / 41$ & 192.3 & 15.2 & 250 & 110 \\
\hline $\mathrm{M} 30$ & $77 / 19$ & 12.2 & 8.0 & 500 & 100 \\
\hline $\mathrm{M} 40$ & $85 / 23$ & 26.9 & 14.8 & 550 & 110 \\
\hline $\mathrm{M} 50$ & $92 / 32$ & 57.2 & 19.2 & 350 & 115 \\
\hline $\mathrm{M} 60$ & $96 / 43$ & 136.2 & 21.3 & 325 & 120 \\
\hline
\end{tabular}

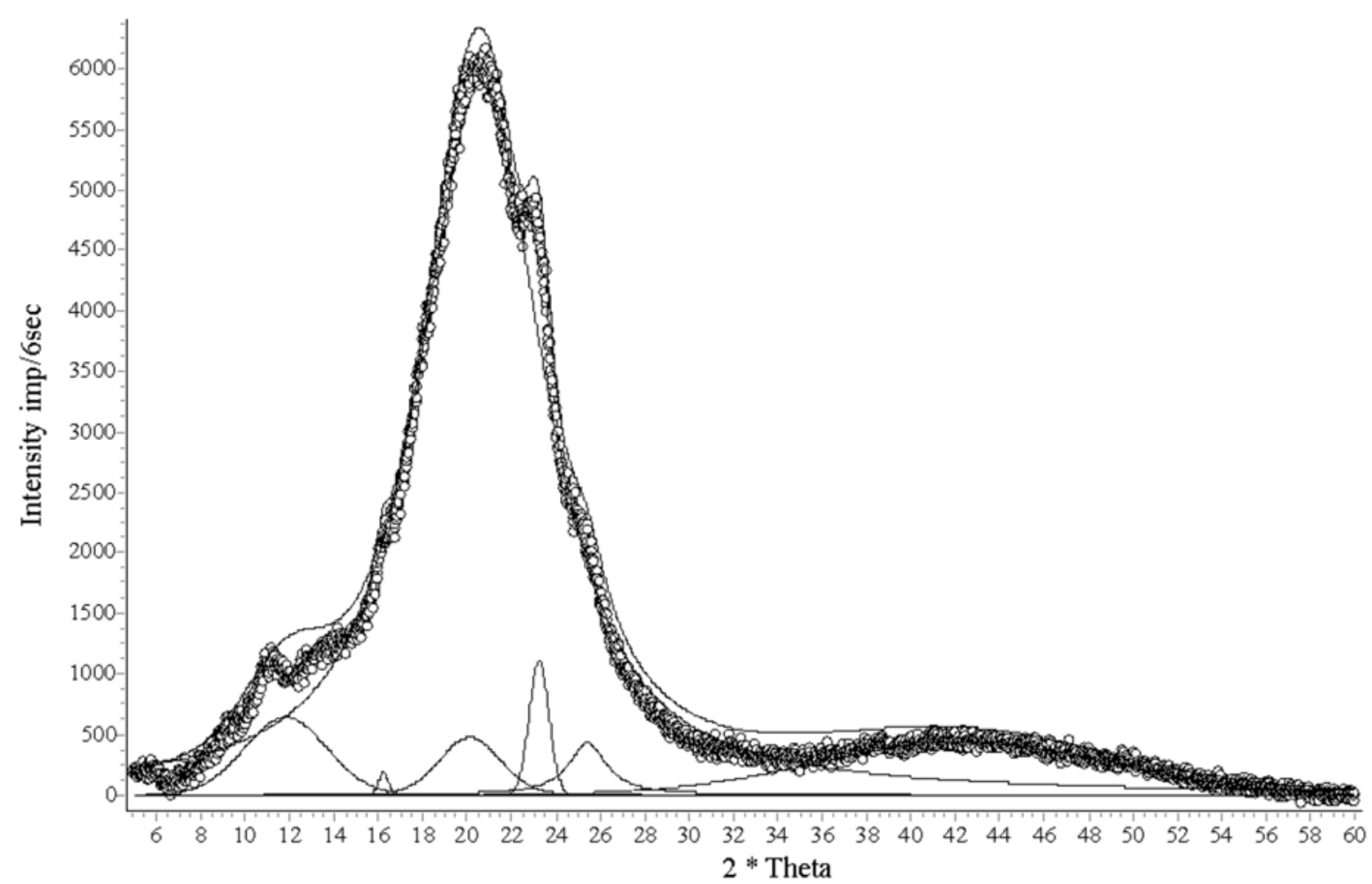

Figure 5. The XRD curve (points) of polymer H30 resolved into crystalline and amorphous peaks (solid line)

hard segments (50 and $60 \mathrm{wt} \%$ ) were chosen, and the obtained phase images are given in Figure 4. These data exhibit the heterogeneous bulk morphology in all the polymers examined with distinct differences for the HDIand MDI-based polymers. In the polymers from HDI the preferred linear direction in the orientation of the rodlike hard domains is observed, while in the polymers from MDI they are randomly embedded in the soft-segmentrich matrix. This correlates with the results of DSC analysis which showed in the HDI series the $\Delta H_{\mathrm{m}}$ values almost twice as high, as well as smaller differences between the $T_{\mathrm{m}}$ values of segmented polymers and suitable regular polymer than in the MDI series.

\section{X-ray diffraction (XRD) analysis}

The XRD analysis was done for all the TPUs. The results of the analysis of the XRD patterns by the WAXSFIT program are presented in Table 3 , and on the sample plot in Figure 5, whereas the XRD patterns of the HDI-based polymers can be found in Figure 6.

Considering the full width at half maximum (FWHM) values and the fact that peaks with high area (at $2 \theta=11.1$ $-12.3^{\circ} ; 19.5-20.9^{\circ} ; 39.9-42.7^{\circ}$ ) are wide, it can be stated that the polymer samples showed slight long dis- tance order. The peaks originating from a crystalline phase (with FWHM $=0.5-1.4^{\circ}$ ) have a small area, and so the degree of crystallinity determined for these polymers (calculated as the ratio of the sum of crystalline peak areas to the total sum of crystalline and amorphous peak areas) equals only $0.9-2.6 \%$.

\section{Mechanical properties}

Shore A/D hardness and tensile properties of all the TPUs were studied after pressing at $100^{\circ} \mathrm{C}$ to $120^{\circ} \mathrm{C}$ under the pressure of $\sim 10-30 \mathrm{MPa}$. Pressing temperatures and the numerical data for the polymers are given in Table 4.

As it is evident from the data presented in Table 4, the polymers with a lower modulus of elasticity and higher elongation at break were obtained from MDI. TPUs of the MDI series (with the exception of M30) were additionally characterized by similar hardness but higher tensile strength in comparison with TPUs of the HDI series. On the whole, in both series of polymers the increased hard-segment content resulted in the increased hardness, modulus of elasticity and tensile strength, as well as in the decreased elongation at break. 


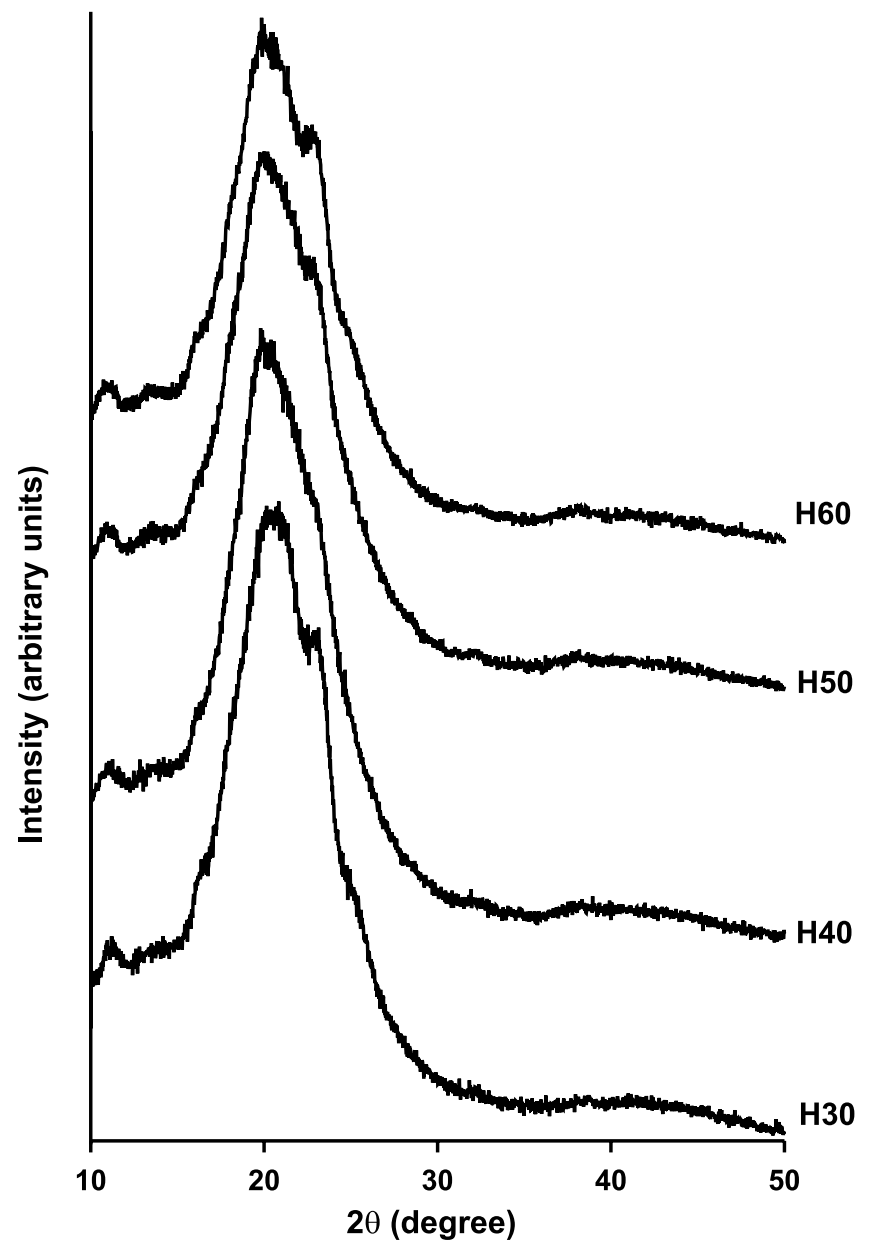

Figure 6. The XRD patterns of the HDI-based TPUs

\section{CONCLUSIONS}

The two series of novel TPUs, with the hard-segment content of $30-60 \mathrm{wt} . \%$, were synthesized by a classical one-step melt polymerization from PHC of $\bar{M}_{n}=2000$ as a soft segment, HDI or MDI and 6,6'-[methylenebis(1,4-phenylenemethylenethio)]dihexan-1-ol (diol H) as an unconventional chain extender. All the TPUs showed almost amorphous structures. The HDI-based TPUs were characterized by lower $T_{\mathrm{g}} \mathrm{s}$, a higher degree of microphase separation but lower elongations at break and generally poorer tensile strengths than the MDI-based analogs.

\section{LITERATURE CITED}

1. Wirpsza, Z. (1993). Polyurethanes: chemistry, technology and applications; New York, USA: Ellis Horwood.

2. Tanzi, M.C., Mantovani, D., Petrini, P., Guidoin, R. \& Laroche, G. (1997). Chemical stability of polyether urethanes versus polycarbonate urethanes. J. Biomed. Mater. Res. 36(4), $550-559$.

3. Hsu, S.H. \& Lin, Z.C. (2004). Biocompatibility and biostability of a series of poly(carbonate)urethanes. Colloid. Surface. B 36(1), 1-12. DOI: 10.1016/j.colsurfb.2004.04.003.

4. Eceiza, A., Larranaga, M., De la Caba, K., Kortaberria, G., Marieta, C., Corcuera, M.A. \& Mondragon, I. (2008). Structure-property relationships of thermoplastic polyurethane elastomers based on polycarbonate diols. J. Appl. Polym. Sci. 108(5), 3092-3103. DOI: 10.1002/app.26553.

5. Christenson, E.M., Dadsetan, M., Wiggins, M., Anderson, J.M. \& Hiltner, A. (2004). Poly(carbonate urethane) and poly(ether urethane) biodegradation: In vivo studies. J. Biomed. Mater. Res. 69A(3), 407-416. DOI: 10.1002/JBM.A.30002.

6. Zdrahala, R.J. (1996). Small caliber vascular grafts. 2. Polyurethanes revisited. J. Biomater. Appl. 11(1), 37-61.

7. Resiak, I. \& Rokicki, G. (2000). Modified polyurethanes for biomedical applications Polimery-W. 45(9), 592-602.

8. Kultys, A. (2003). Sulfur-containing polymers. In Mark, H.F. (Ed.), Encyclopedia of polymers science and technology (3rd ed., Vol 4). Hoboken, New Jersey: Wiley.

9. Hirano, H., Kadota, J., Agari, Y., Harada, T., Tanaka, M. \& Hasegawa, K. (2007). Linear polymers with sulfur in the main chain. IV. Synthesis of thermotropic liquid-crystalline polythioesters based on 4,4'-biphenyldithiol with excellent adhesive properties. Polym. Eng. Sci. 47(3), 262-269. DOI: 10.1002/pen.20702.

10. Kricheldorf, H.R. \& Schwarz, G. (2007). Poly(thioester)s. J. Macromol. Sci. A 44(4-6), 625-649. DOI: 10.1080/ 10601320701285094.

11. Kultys, A., Podkościelny, W. \& Majewski, W. (2000). Polyurethanes containing sulfur. II. New thermoplastic nonsegmented polyurethanes with diphenylmethane unit in their structure. J. Polym. Sci. Part A Polym. Chem. 38(10), 17671773. DOI: $10.1002 /($ SICI)1099-0518.

12. Rabiej, M. \& Rabiej, S. (2006). Analysis of X-ray diffraction pattern of polymers by means of WAXSFIT computer program (in Polish). Bielsko-Biała, Poland: ATM.

13. Xu, Y., Petrovic, Z., Das, S. \& Wilkes, G.L. (2008). Morphology and properties of thermoplastic polyurethanes with dangling chains in ricinoleate-based soft segments. Polymer 49(19), 4248-4258. DOI: 10.1016/j.polymer.2008.07.027. 